\title{
Contos de fada - uma experiência no processo de alfabetização com crianças e professores das classes
}

populares.

\section{Fairy tales: an experience in the literacy process with lower class children and teachers.}

\author{
Ana Maria de Paula SIQUEIRA
}

\begin{abstract}
RESUMO
A investigação desse trabalho diz respeito aos anos compreendidos entre 1984 e 1996, período de vigência da implantação do Ciclo Básico de Alfabetização e da Jornada Única, no Estado de São Paulo. Esta investigação procurou levar em conta o problema de acesso e permanência ou evasão de crianças das classes populares, com proposta diferenciada de inovação em alfabetização. A pesquisa ora descrita nasceu de uma preocupação com o elevado número de crianças excluídas do processo de alfabetização e também pelo rendimento insatisfatório daquelas que se encontram matriculadas em nossas escolas. Durante a investigação trabalhamos com 38 classes e professores de Ciclo Básico, professores de Língua Portuguesa e aproximadamente 1.200 crianças (sem pré-escola e retidos) com uma proposta construtivista de alfabetização para crianças das classes populares. Fundamentamo-nos nas teorias de Jean Piaget, Emília Ferreiro, Ana Teberosky, e outros, para discussão, reflexão, análise e realização das atividades feitas em sala de aula pelas crianças. Essas atividades resultaram a princípio, em grande fonte de possibilidades para 0 prosseguimento das investigações, pois boa parte delas mostrava que, no repensar da prática, juntamente com o professor poder-se-ia propor alternativas de trabalho no cotidiano escolar. Assim, numa atividade coordenada - de preparo, aplicação, acompanhamento e avaliação do cotidiano do professor- foi observado como as crianças se apropriaram da escrita passando a utilizá-la num contexto extra-escolar. Voltamos um breve lhar para a situação da escola nas décadas anteriores, com o intuito de situar melhor o contexto atual e apresentar uma experiência, inspirada na teoria construtivista, que nos levou a alguns resultados que julgamos positivos e animadores de novas experiências.
\end{abstract}


Palavras-chave: contos de fada, alfabetização/ leitura/ escrita, sucesso escolar, construtivismo.

\begin{abstract}
This work's investigation is about the period from 1984 to 1996, when the Literacy Basic Cycle and Unique Journey were implanted in Sao Paulo. It focuses the problem of children's access and permanence in school. It is also focuses the problem of lower class children's evasion. The purpose of this study is to propose new forms to teach children to write and read. This research was born of the preoccupation with the high number of excluded children from the literacy process and with the unsatisfactory results obtained by many children who study in our schools. In order to investigate the problem, 38 Literacy Basic Classes and their teachers, besides 1200 children (which did not attend kindergarten classes or failed) took part of a constructivist literacy proposal for lower class children. This study was based on the theories of Jean Piaget, Emília Ferreiro, Ana Teberosky, among others. They were used to establish discussions, reflections and analysis of the activities made in the classroom. The first result of these activities concerns to help us to rethink about the practices used by the teachers in the classroom. The teachers were analyzed and evaluated and they had our support to develop new strategies to help children to learn how to write and read. The results showed us that children could not only acquire the writing but also use it in outside school situations. We also paid attention to the past school's situation in order to explain how it is nowadays and to show our experience, based on a constructivist theory, which presented some positive results.
\end{abstract}

Index terms: Fairy Tales, literacy - reading and writing, scholar success, constructivism.

\title{
Introdução
}

O Objetivo da escrita aqui apresentada é mostrar como ocorreu a assimilação dos mecanismos de leitura e escrita, para o exercício da 
cidadania, num grupo de crianças das classes populares que, por caminhos pedagógicos inovadores superaram com “sucesso o fracasso escolar”, com uma experiência feita a partir da reescrita de textos do gênero “ contos de fada”. Quando me refiro ao sucesso das crianças, procuro apontar também quais foram os fatores políticos educacionais, teóricos e práticos e as normas legais que contribuíram para o mesmo. Minha experiência como alfabetizadora, capacitadora da Fundação para o Desenvolvimento da Educação, no Curso de Alfabetização Teoria e Prática, e, como Assistente Técnico Pedagógico do Ciclo Básico de Alfabetização, ajudou-me na coleta e compilação de vários dados, justificando "sucesso escolar" entre as crianças das classes populares.

Essa investigação procurou levar em conta o problema do acesso e permanência ou evasão das crianças das classes populares, com proposta diferenciada de inovação em alfabetização. Portanto, a investigação nasceu da preocupação com o elevado número de crianças excluídas do processo de alfabetização e também pelo rendimento insatisfatório daquelas que se encontravam matriculadas em nossas escolas. Durante a investigação trabalhamos com um grupo de professores de Língua Portuguesa, professores do Ciclo Básico de Alfabetização e aproximadamente 1.200 crianças (da periferia da Zona Leste de São Paulo, onde se concentra grande parte da população de baixa renda) sem pré-escola e retidos há mais de dois ou cinco anos, com uma proposta construtivista de alfabetização para crianças de classes populares. Consideramos essa população significativa, uma vez que o aumento da oferta de vagas e matrículas não havia garantido a efetiva permanência dos alunos matriculados nas escolas da região e a qualidade do ensino oferecido a eles. O curso Alfabetização: teoria $e$ prática dos Projetos especiais da Fundação para o Desenvolvimento da Educação (FDE) facilitou o trabalho de investigação, uma vez que foi através dos encontros semanais com o grupo de professores envolvidos, que tivemos possibilidade de acompanhar a construção do conhecimento das 
crianças para a aquisição da leitura e da escrita. Fundamentamo-nos nas teorias de Jean Piaget, Emília Ferreiro, Ana Teberosky, e outros, para discussão, reflexão, análise e realização das atividades de reescrita de textos do gênero contos de fada, feitas em sala de aula. Nosso objetivo era que a escola atuasse no sentido de que a criança aprendesse a ler e a escrever, para se tornar um sujeito produtor de texto inserindo-se num contexto social mais amplo, porque de acordo com a teoria da Psicogênese, cabe à escola a tarefa social de ensinar e a criança não tem a condição de transpor sozinha a interação com o objeto que fora da escola não teve a oportunidade de conhecer. As atividades criativas elaboradas pelas crianças resultaram, a princípio, em grande fonte de possibilidades para o prosseguimento das investigações, pois boa parte delas mostrava que, no repensar da prática, juntamente com o professor poder-se-ia propor alternativas de trabalho no cotidiano escolar. Assim, numa atividade coordenada de preparo, aplicação, acompanhamento e avaliação do cotidiano do professor pudemos observar como as crianças apropriam-se da leitura e escrita passando a utilizá-las num contexto extra-escolar, em cartas enviadas à pesquisadora e outros participantes do processo.

\section{Metodologia de pesquisa}

Ao tentar detectar os fatores que ainda mantinha alto o índice de crianças sem domínio dos mecanismos de leitura e escrita, no Ciclo Básico de Alfabetização, que buscamos realizar o trabalho ora descrito, julgando ser a sua aplicação uma das maneiras de atenuar o problema. Partindo da premissa de que a construção de conhecimentos é tarefa que cabe particularmente ao professor, procurou-se discutir durante o curso as seguintes questões: a) O problema da alfabetização nas classes populares. b) O trinômio teoria/ preconceito /mito - “crianças das classes populares não 
aprendem”. c) O professor como interventor da aprendizagem, na formação de leitores e escritores. d) A construção do conhecimento, baseada nos teóricos construtivistas, aliando teoria aplicada à prática. e) O uso de textos do gênero Contos de Fada, para atingir a produção de outros textos coesos e coerentes. f) Materiais alternativos para um trabalho engajado com o projeto do curso. g) Sugestões de atividades aliando teoria à prática. h) Enfim, a aquisição e o domínio da leitura e escrita.

Como ponto de partida foram propostas atividades com as quais os professores já estavam habituados, para não lhes tolher a liberdade de ação pedagógica. Para nortear o trabalho do professor priorizamos: Texto/ Produção Oral - a ênfase na oralidade tinha como intuito valorizar a competência lingüística da criança, enquanto falante da língua materna; Texto/ Produção Escrita - como os professores compreenderam que as crianças podiam ler e escrever, mesmo antes de adquirirem os mecanismos básicos de leitura e escrita, ficava claro que só se aprende a ler lendo, e, só se aprende a escrever escrevendo, o que tornou espontânea a relação da criança com a escrita. As crianças, a princípio, deveriam ouvir um conto narrado pelo professor e reescrevê-lo. Posteriormente um conto deveria ser assistido pela televisão e reescrito e, finalmente numa outra etapa, tentariam fazer a leitura e escrita de um conto a partir do contato prévio com obra da Literatura Infantil.

Optamos por sortear algumas produções escritas das crianças para compor corpus do presente artigo. 


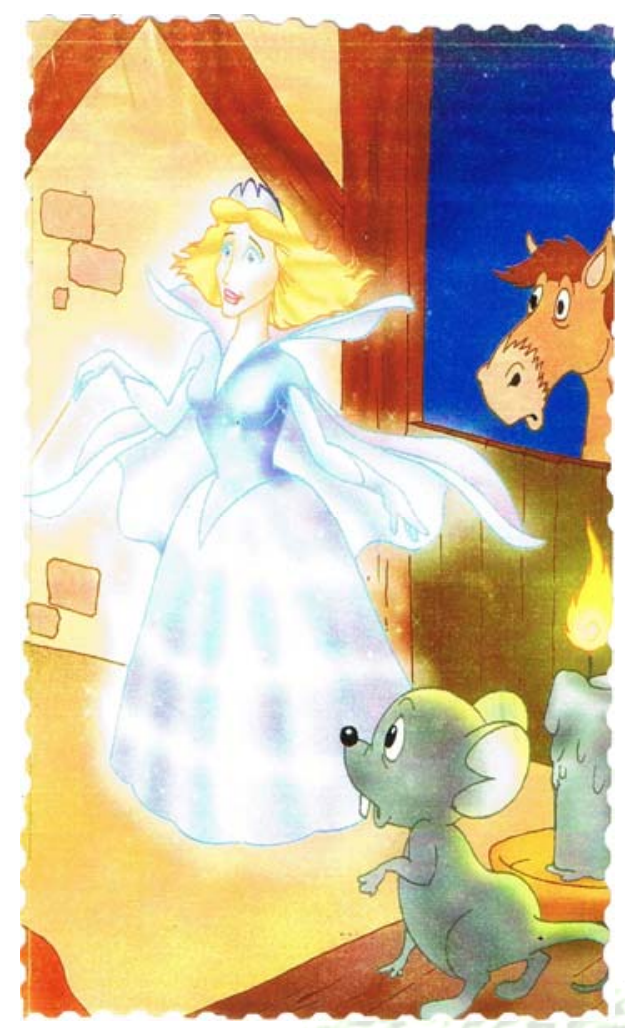

“Cinderela" - Patrícia Juliana - 7 anos

Era rei um filia e rei se caso.

O rei morreu e a Cinderela ficou com a madasta.

A madasta ficava chemmendo a Cinderela

Cinderela cinderela javou javou.......

Cinderela que ir comigo no baile meninas mispere e

Secolar é meu e se vistido é meu

- fada madrinha pegou a vara majica e empeistou o

vistidio cinderela meia noite voce ficara sem 0

vistidio e sem a caroça e votaralnormau........

e ela foi a obaile e dansou com prisipi

O jaé meia noite euprisiso eu vou imbora

O ratinho pegou a xave do bonso e subiu ea prio

O quarto e ela saio. E vivio felizes para sempre..

Nessa reescrita, as marcas da oralidade podiam ser vistas no lugar de parágrafos, pontuações e entonações, por exemplo:

- Cinderela! Cinderela! (Cinderela cinderela)

— Já vou! Já vou! ( javou javou)

- Meninas me esperem! (meninas miespere)

— Oh! Já é meia noite! Eu preciso ir embora. (O jaé meia noite euprisiso eu vou imbora)

— E voltará ao normal (e votaralnoormau) 


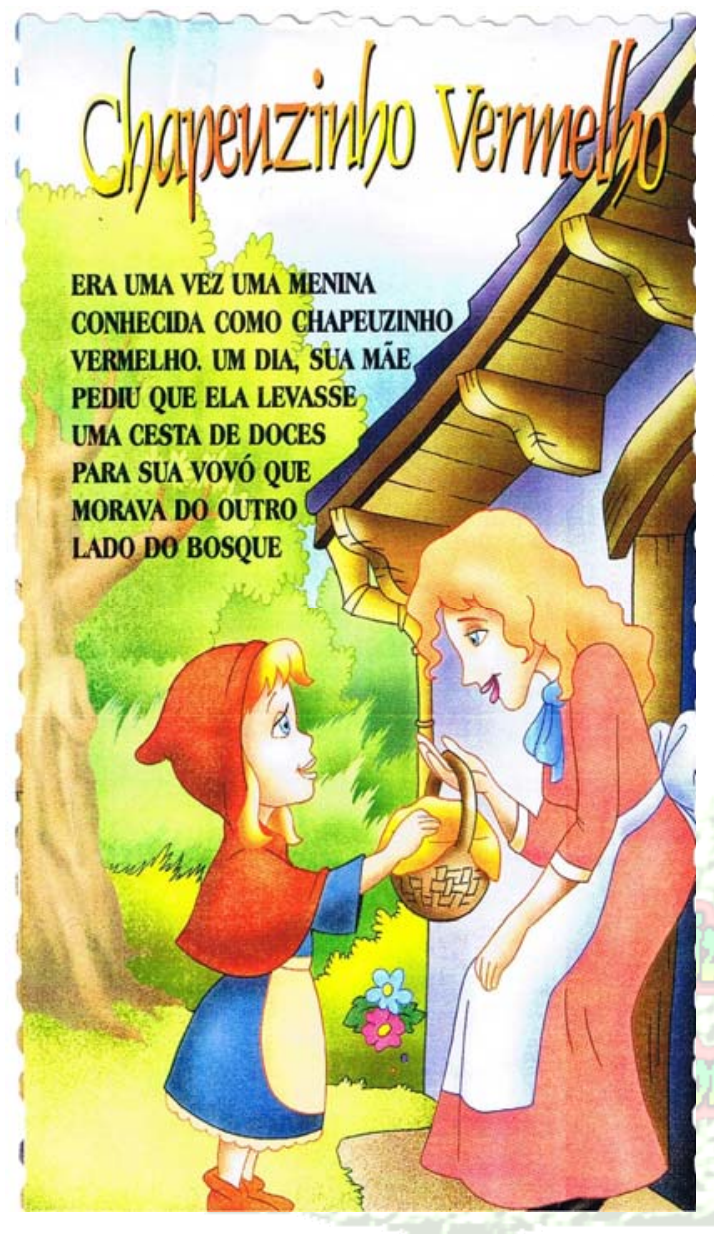

"O Chapeuzinho Vermelho" -

Fábio Antonio - 12 anos

( $1^{a}$ - escrita $)-18 / 05 / 93$

eumveiseminina samada

chapaaeuinhovermeio

temcaipuetoca diu savezario.

Era uma vez uma menina chamada

Chapeuzinho Vermelho que tem

Capuz e toca que a vovó lhe deu de aniversário.

- a mãe faisedozinho e minina vai levaparavovo? Naofalalobomau queloboomau comeclinacia.

A mãe fez docinhos e disse, menina leva para a vovó. Não fala com o lobo mau que o lobo mau come criancinha.

cqvssetafezenoaiseulobomau? (cqlê como qui, qui).

O que é que você está fazendo aí seu lobo mau?

- geiramina netina.

Cheirar a minha netinha. 


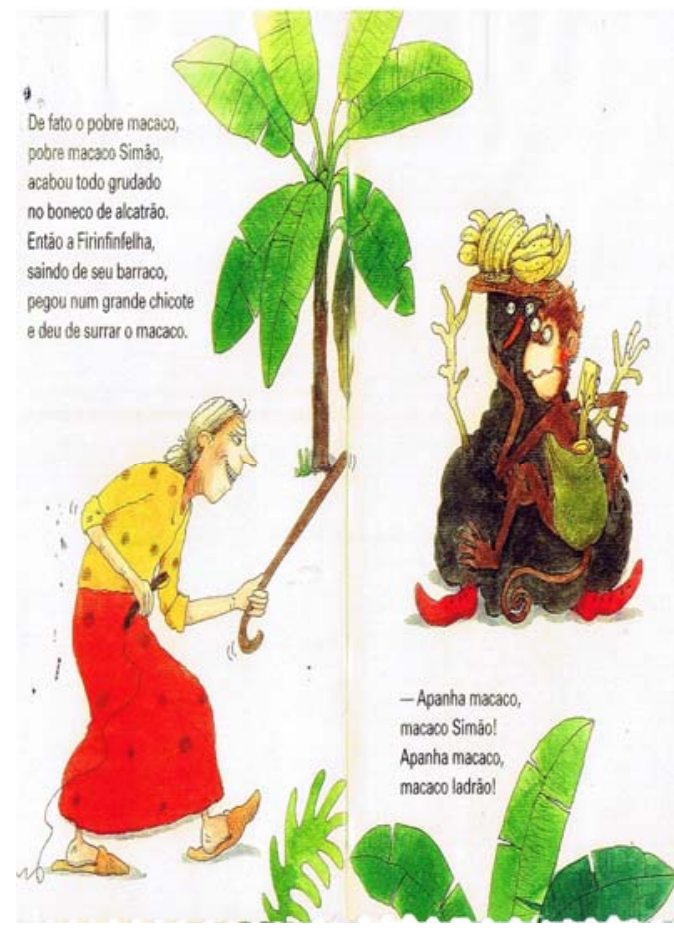

“O macaco e a velha” - Fábio

Antonio - 12 anos

( $2^{\mathrm{a}}$ - escrita $)-17 / 06 / 93$

- A velha morava lainsima do moro.

E na casa e na frente tem o jardim

E a trais da casa tem pé de bananeiras

Eai jatava madurinas e não da papega as banana.

- Eai ela viu o macaco

paseando e xamou o macaco.

"Seu macaco filo da mãe"

Sadai sua boneca senão vou tida

um tapa pau

Misouta sua boneca senão vou tida uma tapa prau”.-

Tanto quanto Patrícia Juliana, Fábio Antonio ainda não domina os recursos que a Língua Portuguesa lhe oferece. Portanto, escreve de acordo com suas hipóteses, fazendo uso da oralidade, transpondo- a para a produção escrita. Exemplo: "lainsima”, “saidai”, “jatava”, “papega”, "madurinas" e "misouta”.

Observamos que nas reescritas havia sempre a introdução do texto, intercalada de pequenas ações, seguida de desenvolvimento e conclusão, conservando-se, assim, a seqüência lógica das ações. Os finais são súbitos, e às vezes ocorre o aparecimento de personagens que surgem apenas para cumprir sua ação no discurso e estes desaparecem sem nenhuma explicação, como a fada madrinha. 
Nestas reescritas, as marcas da oralidade podem ser vistas no lugar dos parágrafos, ortografia, pontuações e entonações. Outras marcas puderam ser vistas quando as crianças buscavam a norma culta para produzir seu texto, tais como, parênteses, aspas, travessão, interrogação, muitas vezes colocadas no texto, talvez, mais por hipótese estética ou espacial, do que com intenção funcional.

\section{Resultados}

Após a análise de várias produções, colocava-se ao grupo que, ao professor, enquanto interventor no processo ensino-aprendizagem, caberia mostrar às crianças que quando se substitui as marcas da oralidade por recursos que são próprios ao texto, estes lhes possibilitariam uma estrutura mais clara de reescrita e dariam maior qualidade às suas produções. Nosso objetivo era contribuir na formação do grupo de professores para que a escola atuasse no sentido de que a criança aprendesse a ler e a escrever a partir dos contos de fada, para se tornar um produtor de textos, inserindo-se num contexto social mais amplo.

Notamos que a oportunidade de aplicação das noções adquiridas é que leva a criança à efetivação da aprendizagem. Ao ensinar a aprender havia a preocupação com o desenvolvimento e preparo para o que vai além das exigências da escola por parte de todos. Dessa maneira, nossa proposta com o grupo era de que a escrita transcendesse o seu aspecto exclusivamente escolar, pensar, representar, comunicar com prontidão, para se tornar reconstrução, construção e redefinição da prática pedagógica do professor.

No processo de escrita dos contos de fada, observamos que na aproximação do nível alfabético ao ortográfico, as crianças reviam suas hipóteses formuladas, registrando a forma pela qual haviam optado. No 
início, entretanto, para as crianças era difícil fazer a reescrita. Elas tinham assimilada uma imagem de alfabetização em que se aprende primeiro as vogais, sílabas simples, sílabas complexas e assim sucessivamente. Colocar o processo de ensino-aprendizagem, tendo como base o Projeto Político Pedagógico da escola e o trabalho professor/aluno constituiu um grande desafio para o grupo, pois o conhecimento teórico que mostrava uma grande distância entre a teoria e a prática tornou-se objeto de reflexão sobre o ensinar e aprender na escola.

Assim, o trabalho do grupo abriu várias possibilidades de reflexão para mudanças sobre o processo de aprender na escola e o entendimento pedagógico como opção por essa ou aquela teoria, como instrumental para organização de sua ação como educador, compreendendo o aluno como sujeito da aprendizagem.

\section{Segundo Ferreiro e Teberosky:}

O sujeito que conhecemos através da teoria de PIAGET é um sujeito que procura ativamente compreender o mundo que o rodeia, e trata de resolver as interrogações que este mundo provoca. Não é um sujeito que espera que alguém que possui um conhecimento o transmita a ele, por um ato de benevolência. É um sujeito que aprende basicamente através de suas próprias ações sobre os objetos do mundo, e que constrói suas próprias categorias de pensamento ao mesmo tempo que organiza seu mundo. A teoria de Piaget não é uma teoria particular sobre um domínio particular, mas sim um marco de referência teórico, muito mais vasto, que nos permite compreender de uma maneira nova “qualquer" processo de aquisição de conhecimento (1993, p. 26).

O estudo da teoria dos autores construtivistas contribuiu para que os professores entendessem a forma como ocorre o aprendizado, os objetivos da educação básica formal, e como fazer a sua intervenção pedagógica, no processo de aquisição de leitura e escrita. Portanto, baseando-se em teorias 
construtivistas, o grupo pôde analisar como se dá o processo de alfabetização, a compreensão desse processo, buscando saber que concepções de língua escrita a criança tem, e como usá-la como função social. Assim, num trabalho com o uso de textos do gênero contos de fada pudemos observar como as crianças se apropriaram da escrita e passaram a utilizá-la num contexto extra-escolar para comunicação com outras pessoas, a partir de várias cartas envidas pelas crianças, para o Diretor da Fundação para o Desenvolvimento da Educação, para o Papai Noel, para a pesquisadora conforme os exemplos:

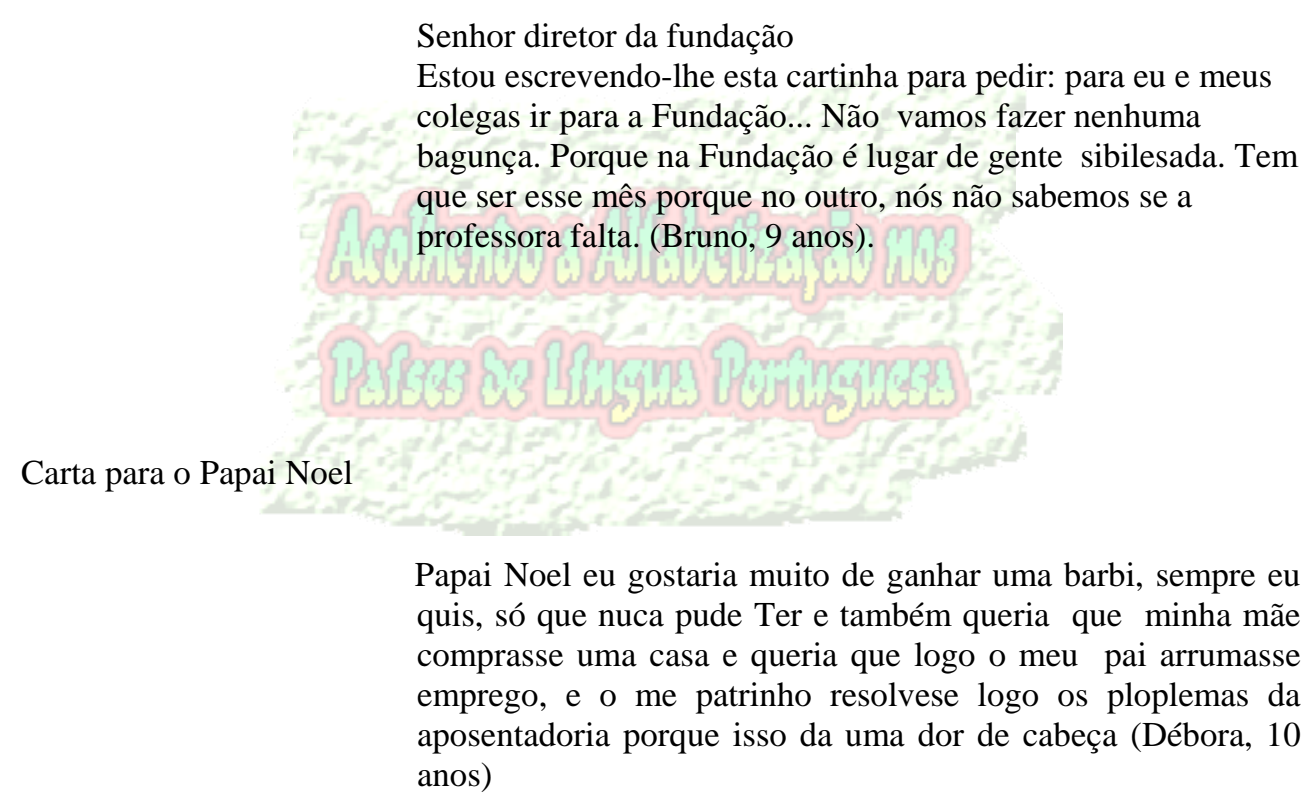

Senhor diretor da fundação

Estou escrevendo-lhe esta cartinha para pedir: para eu e meus colegas ir para a Fundação... Não vamos fazer nenhuma bagunça. Porque na Fundação é lugar de gente sibilesada. Tem que ser esse mês porque no outro, nós não sabemos se a professora falta. (Bruno, 9 anos).

Papai Noel eu gostaria muito de ganhar uma barbi, sempre eu quis, só que nuca pude Ter e também queria que minha mãe comprasse uma casa e queria que logo o meu pai arrumasse e a me patrinho resolvese logo os ploplemas da anos)

O uso da escrita como função social também, surgiu num processo de interlocução entre as crianças e a pesquisadora. As cartas, vindas através dos professores, deixavam claro que as crianças estavam fazendo uso da escrita como função social, isto é, usando o "modo de dizer por escrito”. 
Eu quero reclamar, que a professora está dando muita lição e estória. E é só lição, ela quase não dá desenho para nós pinta. Quando eu chego na classe eu já vejo lição de casa, e eu espero que isso mude (Alexandre, 9 anos).

E agora eu e meus colegas estamos reclamando muito de tanto trabalho que nóis feiz. E nóis feiz tanto trabalho que vou te falar! Nós queremos um trabalho de dezenho e colagem, porque nós só faiz estória e lição e prova (Fernando, 9 anos).

Estou escrevendo está carta é pelo trabalho que você passa para a professora e ela passa para nós. Eu e meus colegas queríamos que a senhora mande menos lição. Falasse para a professora deixar de dar estórias de livro e filme comprido (Raphael, 12 anos).

Estou feliz com a classe, só que o problema é a professora. A professora não passa filme, não dá desenho, não conta histórias, só passa problema, arme e efetue e resolva as sentenças. Estou com saudades das histórias que fazíamos. Gostaria de recomeçar dinovo (Denise, 11 anos).

Estou escrevendo esta carta com muita saudades dos nossos trabalhos. Queria que você fosse lá na escola para nós ter uma conversa. E a professora não tem nasa a ver com isso. Mas venha logo, nós estamos esperando (Cristiane, 10 anos).

eu quero agradecer a você de perto, mas não dá então: vou agradecer por esse papel. Eu quero te agradecer por eu saber ler e a escrever e a professora também porque ela também já ensinou muito (Francine, 9 anos). 
A partir dos textos, tipo carta, escritos pelas crianças, foi possível constatar a veracidade da assertiva de Ferreiro:

\footnotetext{
Aprender a grafar as palavras, ou reconhecer as palavras já grafadas, é apenas uma ínfima porção da aprendizagem da língua escrita. Aprender a "abrir" e "fechar" por escrito é tão importante como aprender a fazê-lo na linguagem oral. É difícil levar a cabo uma comunicação bem sucedida, cara a cara, quando não se domina as maneiras de abrir e fechar uma conversa. Quando conseguimos fazê-lo, pode-se dizer muitas coisas com um texto, e, quando se deixam as crianças falarem (por escrito) elas falam mesmo, e isto dá muito medo aos educadores (1993, p.23).
}

Aqui a psicogênese da língua escrita deu sua contribuição fundamental, demonstrando na aquisição da escrita, seu caráter evolutivo, comprovando seu desenvolvimento nas elaborações cognitivas das crianças, nas produções dos textos. Ficou claro, ainda, que para se alfabetizar, não há necessidade de se estabelecer regras de fixação entre os sons e as letras, prontidão, percepção, maturidade ou coordenação motora, mas oferecer às crianças situações reais de aprendizagem, com alternativas e tomadas de decisão, para que elas saiam do estágio de linguagem oral para a aquisição prática da escrita.

As produções relatadas mostram que a proposta dos Contos de Fada para alfabetização de crianças das classes populares funcionou, tanto para a alfabetização - no sentido mais amplo - como para o exercício da cidadania por pequenos cidadãos, que passaram a questionar o “poder” instituído na sala de aula.

\section{Considerações finais}


Através desse uso observamos ainda que as informações obtidas através da apreensão, apropriação e transformação de significados oriundos dos contos de fada, num mundo cheio de milagres, mostravam às crianças que cada informação contida na língua escrita nos contos servia agora para a comunicação. O índice de quase 92\% de alfabetização das crianças inseridas no processo mostrou que esta comunicação, bem como a construção do conhecimento se deveu às atividades até então desenvolvidas com a oralidade, a leitura e a escrita, que reciprocamente se entrelaçaram para que atingíssemos o objetivo: leitura e escrita de texto. Para o grupo, pesquisadora e professores, o uso da língua nas produções foi entendido como verdadeira expressão de uma cultura, porque houve por parte de todos. Ou seja, observamos o respeito e a liberdade às formas como a criança se expressava para atingir a norma padrão a fim de se comunicar com outras pessoas; intervenções, que ocorriam, sem interromper o processo criativo da criança, acreditando-se no potencial lingüístico da mesma; caminhos de busca para ampliação do vocabulário de todas as crianças; grande incentivo à liberdade de expressão, para que cada criança, dentro de suas possibilidades, construísse sua própria visão de mundo; limites como são indispensáveis ao desenvolvimento, houve por vezes a necessidade do seu estabelecimento. Eles se fizeram necessários em função das estruturas individuais, pois acreditamos não bastar apenas oferecer às crianças oportunidades de aprendizado ou orientá-las nesse sentido, mas também, em várias ocasiões, mostra-lhes as interdições necessárias, pois essas significavam apoio, ou o próprio substantivo da segurança para a criança; colocação das crianças em situações reais de escrita, a fim de que, a partir de certas confrontações, pudessem se situar de forma mais realista na aplicação efetiva da aprendizagem escolar no seu cotidiano.

A circulação das produções das crianças mostrou-nos que as mesmas serviram, enquanto função social, para apreenderem o mundo e confirmarem suas idéias e pensamentos sobre leitura e escrita, num mundo 
onde a cultura oral e, principalmente, a escrita é muito importante para a formação ideológica e alcance do sonho de ascensão social pequeno burguesa. Essa aprendizagem que consideramos significativa, muito mais que decorrência de um processo de maturação intelectual, permitiu a construção de um processo de auto-descoberta e um exercício de vontade de constituir-se uma via de acesso aos bens culturais e ao exercício da cidadania por crianças das classes populares, que se iniciaram no processo de Alfabetização. A permanência do professor alfabetizador, com a mesma turma, durante os dois anos da pesquisa foi considerada conveniente e benéfica do nosso ponto de vista pedagógico, pois propiciou a oportunidade de se dar seqüência ao processo de ensino-aprendizagem sem a retomada de conteúdos pelos alunos defasados em idade-série. Além disso, levou-se em consideração a criança como um ser que já chega à escola com um potencial lingüístico. Este potencial, explorado através dos contos de fada, tornou-se durante a investigação, a forma mais rápida e conveniente de transformar o processo de aprendizagem em conteúdo de ensino. Em síntese, para que os novos caminhos descobertos tornassem um processo de aprendizagem realmente efetivo, julgou-se conveniente acompanhar o professor no momento de transformar a teoria em prática, orientando-o na maneira de interferir no processo de aquisição de leitura e escrita, através de mudanças na sua postura e metodologia em sua prática, na sala de aula.

\section{Referências bibliográficas}

FERREIRO, Emilia, TEBEROSKY, Ana (1986). Psicogênese da Língua Escrita. Porto Alegre: Arte Médicas.

(1993). A Formação de Leitor. Revista de La Educación del Pueblo, Montevidéu, no 51/ 7/ 92, publicado: GIZ. 
PIAGET, Jean (1976). A equilibração das estruturas cognitivas. Rio de Janeiro: Zahar.

Paulo: Abril.

(1978). A epistemologia genética. Os Pensadores. São

(1994) O juízo Moral na criança. São Paulo: Summus.

\section{Autora:}

\section{Ana Maria de Paula Siqueira}

Professora orientadora (PO) e videoconferencista do PEC - Formação Universitária na PUC de São Paulo desde 2001, e professora adjunta da Universidade Guarulhos, São Paulo, ministrando aulas nos Cursos de licenciatura, das disciplinas pedagógicas, (Psicologia da Educação, Didática, Prática de Ensino e Estágio Supervisionado, e Metodologias), desde 1987. ampsiqueira@uol.com.br

\section{Como citar este artigo:}

SIQUEIRA, Ana Maria de Paula. Contos de fada - uma experiência no processo de alfabetização com crianças e professores das classes populares. Revista ACOALFAplp: Acolhendo a Alfabetização nos Países de Língua portuguesa, São Paulo, ano 2, n. 4, 2008. Disponível em: $<$ http://www.mocambras.org> e ou <http://www.acoalfaplp.org>. Publicado em: março 2008. 